\section{$\mathrm{sent}$}

Marcelo Antônio Chaves Arquivo Público do Estado de São Paulo

teochaves@gmail.com

() https:/lorcid.org/0000-0001-5968-6754

\title{
Arquivos empresariais como fonte para a produção da História
}

\section{Corporate Archives as Source For the Production of History}

\begin{abstract}
Resumo
Os arquivos de empresas são conjuntos documentais orgânicos que guardam informações valiosas sobre a produção da história, em especial sobre a história do trabalho. Entretanto, não são muitas as pesquisas acadêmicas baseadas fortemente em informações extraídas desses arquivos. Este artigo apresenta algumas reflexões sobre as dificuldades e possibilidades de uso desses arquivos para a produção da história.
\end{abstract}

Palavras-chave: arquivos empresariais; história do trabalho; arquivo e história.

\begin{abstract}
The archives of corporations are organic sets of documents that hold valuable information about the production of History, especially about the History of work. However, few are the academic research strongly based on information extracted from these files. This article presents some reflections on the difficulties and possibilities of using these files for the production of History.
\end{abstract}

Keywords: Corporate Archives; History of Work; Archive and History.

\begin{abstract}
A história não se faz com documentos que nasceram para serem históricos, com documentos que só informem sobre o ponto inicial ou o ponto final de algum ato administrativo decisivo. A história se faz com uma infinidade de papéis cotidianos, inclusive com os do dia-a-dia administrativo, além de fontes não governamentais.
\end{abstract}

(Heloísa L. Bellotto).

A escrita da história é dependente, fundamentalmente, da permanência (sobrevivência) de informações registradas em quaisquer suportes documentais; da percepção e leitura desses registros por sujeito(s) que as tornem disponiveis; da análise desses dados e informações; e de narrativa compreensivel ao intelecto humano. As tais fontes documentais (exatamente esses vestígios do passado, remoto ou não) são, portanto, elementos cruciais para 
a escrita da história. Entretanto, vestígios materiais culturais remanescentes do passado não são preservados e legados "naturalmente" entre as gerações, principalmente em sociedades com pouca capacidade e/ou tradição de preservação, o que torna a recuperação de informações do passado dependente de legados acidentais e de difícil explicação de origem.

Agentes sociais categorizados como empresas se constituem em sujeitos políticos relevantes, principalmente em formações sociais articuladas pela produção de mercadorias. Além do potencial construtivo de engenhosas plantas para fins produtivos (que se constituem em complexos documentos arquitetônicos), as empresas são produtoras de bens e serviços (sob a forma de mercadorias) mas também de documentos de arquivo que, por sua posição social (acumuladora de riqueza), têm potencial informativo relevante sobre os contextos históricos nos quais se inserem.

Estudiosos documentalistas conseguem desenhar planos de classificação capazes de representar intelectualmente as funções essenciais e tipos documentais característicos desses agentes sociais, o que nos ajuda a compreender os documentos recuperados dentro dos seus contextos de produção. A abordagem do problema neste artigo transita na interface das áreas da arquivologia e da história.

\section{Arquivos empresariais: colocação do problema}

Arquivos são conjuntos orgânicos de documentos produzidos/ recebidos/ acumulados por um órgão público, uma organização privada ou uma pessoa, no curso de suas atividades, não importando o seu suporte e que, passada sua utilização vinculada às razões pelas quais foram criados, podem ser preservados por seu valor informativo, para fins de investigação científica e testemunho sociocultural. ${ }^{1}$

Derivado dessa definição, os arquivos privados são definidos como conjuntos de documentos produzidos ou recebidos por pessoas físicas ou jurídicas, em decorrência de suas atividades, podendo ser provenientes "de entidade coletiva de direito privado, família ou pessoa", conforme definição do Dicionário Brasileiro de Terminologia Arquivística. ${ }^{2}$

Márcia Pazim Vitoriano complementa:

Os estudiosos do tema dos arquivos privados os categorizam de acordo com a natureza jurídica de seus titulares. 0 primeiro nível refere-se aos arquivos pessoais e institucionais - pessoas físicas e pessoas jurídicas de direito privado. Dentre os arquivos institucionais, podemos identificar um outro nível, entre arquivos de natureza econômica, os chamados arquivos empresariais, e os arquivos de entidades da sociedade civil, ou arquivos sociais, especialmente associações e fundações privadas que desenvolvam ações de natureza social, como associações de classe, entidades educacionais, beneficentes, religiosas entre outras. $^{3}$

Arquivos de "empresas" podem ser encontrados desde tempos remotos da história. Segundo Vitoriano,

1 Heloísa Liberalli Bellotto. "Archivistica, archivos y documentos". In: Associação de Arquivistas de São Paulo (org.), Archivos \& documentos. ARQ-SP, 2015, pp. 3-41 (Tradução do original em espanhol, deste autor).

2 Dicionário Brasileiro de Terminologia Arquivística. Arquivo Nacional: Rio de Janeiro, 2005.

3 Marcia Cristina de Carvalho Pazin Vitoriano. "Acervos Privados no Arquivo Público do Estado de São Paulo: uma visão sobre os fundos institucionais". Revista do Arquivo, 4 (2017), p. 2, disponível em: http://www.arquivoestado.sp.gov.br/revista do arquivo/04/artigo 07.php\#inicio artigo 


\begin{abstract}
A teoria arquivística incorporou estes conceitos desde seus primórdios. No século XIX, a Associação dos Arquivistas Holandeses definia que: os órgãos administrativos e os empregados de entidades privadas também podem originar um arquivo. Há pessoas jurídicas de direito civil, tais como conventos, hospitais, confrarias, sociedades e associações (...) cujos órgãos administrativos ou empregados lavram contratos, recebem cartas, redigem atas etc., tudo no âmbito das suas funções, por onde se assemelham às entidades públicas. Às próprias pessoas privadas é dado possuírem arquivos. 0 negociante, da mesma forma que a sociedade comercial ou a companhia, dispõe de um arquivo, composto do diário, razão, cartas recebidas, cópias das cartas expedidas, e assim por diante. ${ }^{4}$
\end{abstract}

Porém, essa classificação é mais difícil e complexa em sociedades em que as esferas públicas e privadas se confundem. Como exemplo, os documentos de empreendimento concedido pela Coroa Portuguesa a Domingos Ferreira Pereira, em 1765, recriado por Carta Régia em 1810 como "estabelecimento montanístico das minas de Sorocaba, chamado depois de Real fábrica de ferro São João de Ipanema", 5 que formam o arquivo "privado" Fundo Fábrica de Ferro Ipanema, no Arquivo Público do Estado de São Paulo. Não há consenso sobre a classificação desse fundo como sendo de natureza privada.

É na chamada era moderna, predominantemente burguesa, em que se delineia de forma mais clara a noção de público e privado, na qual o Estado assume forma aparente de ente responsável pela "coisa pública" e também por regular aspectos da esfera privada. Portanto, ao falarmos de arquivos empresariais essa expressão adquire mais precisão nesse contexto, não obstante existirem, de fato, desde a Antiguidade.

Ainda assim, mesmo contemporaneamente, o delineamento de arquivos privados podem demandar dificuldades aos arquivistas, principalmente nos casos em que empresas privadas assumem funções que são de interesse público e, eventualmente, podem ser (re)assumidas por entes estatais. São muitos os casos de alternância da natureza jurídica entre empreendimentos privados e estatais com resultantes complexas em relação à custódia desses arquivos nos processos de transição. ${ }^{6}$

Observa-se que, no Brasil, o uso dos arquivos empresariais como fonte de pesquisa histórica parece ainda muito tímido, mas crescente. ${ }^{7}$ Segundo Vitoriano:

No Brasil, o interesse acadêmico pelos arquivos de organizações privadas tem aumentado consideravelmente nos últimos anos. Inicialmente muito focada nas questões macroeconômicas, a História Econômica brasileira passou a se interessar por questões relativas à atuação das empresas como organismos econômicos. ${ }^{8}$

$4 \quad$ Maria Cristina de Carvalho Pazin Vitoriano. "A presença de fundos privados institucionais nos arquivos públicos estaduais do Brasil", In: José Francisco Guelfi Campos (org.). Arquivos privados: abordagens plurais. São Paulo: ARQ-SP, 2016, p. 9. disponível em: http://arqsp.org.br/wp-content/uploads/2017/09/Arquivos privados abordagens plurais e-book.pdf

5 Nilton Pereira dos Santos. A fábrica de ferro São João de Ipanema: economia e política nas últimas décadas do Segundo Reinado (1860-1889). Dissertação de mestrado em História Econômica, Universidade de São Paulo, 2009.

6 Ao analisar a situação dos arquivos privados no Arquivo Público do Estado de São Paulo, Vitoriano alerta sobre algumas dessas dificuldades em relação aos arquivos privados. Ver artigo citado da Revista do Arquivo n 4.

7 Essa adjetivação se justifica quando se compara o caso brasileiro com outras realidades em outros países. As obras de Vitoriano (2011 e 2016), citadas neste artigo, trazem alguma informação sobre experiências estrangeiras em relação aos arquivos privados.

8 Marcia Cristina de Carvalho Pazin Vitoriano. Obrigação, controle e memória: aspectos legais, técnicos e culturais da produção documental de organizações privadas. Tese de doutorado em História Social: Universidade de São Paulo, 2011, p. 42. 
Nos trabalhos historiográficos (principalmente na história econômica), muitas informações são extraídas de revistas, de documentos avulsos de empresas, de jornais e de publicações de entidades de classes (associações, sindicatos, federações etc.). Poucas são as produções historiográficas que se baseiam nos arquivos administrativos das empresas. Vitoriano respalda essa assertiva:

0 que percebemos nos relatos de alguns desses pesquisadores é que muitas vezes as pesquisas limitam-se a analisar documentos de caráter público das organizações, aqueles que legalmente devem se publicados anualmente, como os balanços e relatórios de administração, eventualmente atas de assembleias e outros documentos regularmente registrados nas Juntas Comerciais ou Registros Público, além de noticiário de imprensa. É claro que essa abordagem, apesar de ser constituída por parcela importante do acervo das organizações, poderia ser valorizada com o acesso aos documentos administrativos das organizações, de modo que os pesquisadores pudessem cotejar as reais condições estruturais e conjunturais relacionadas às pesquisas que realizam. ${ }^{9}$

\section{Registros de empresas e o potencial de revelação do contexto histórico}

Os arquivos de empresas são conjuntos documentais preciosíssimos que guardam informações valiosas sobre variados aspectos da história brasileira e não apenas sobre a vertente da economia. Parte dessas instituições de caráter privado perpassa por longos períodos históricos e acumulam informações peculiares para a produção de reflexões sobre o passado. Dependendo do porte, empresas causam impactos estruturantes na economia e transformador da paisagem nos locais onde se instalam, com reverberações em amplas esferas da sociedade. As empresas são partes de cadeias produtivas e mantêm íntima relação com as diversas esferas dos poderes públicos, seja no âmbito do Poder Legislativo, do Executivo ou até mesmo do Poder Judiciário e também nos diversos extratos dos entes federativos, no caso do Brasil. Empresas de grande porte, quando articuladas em variadas formas de rede (desde as legais associações até o formato de cartéis) atuam de forma decisiva em determinadas políticas governamentais, como amplo impacto socioeconômico.

A título de exemplo, basta pensarmos que o golpe civil militar de 1964 no Brasil jamais teria ocorrido ou tido sucesso sem o empreendimento material, político, organizativo e ideológico de centenas de empresas que o garantiram. Se tivéssemos acesso aos arquivos dessas empresas, certamente flagraríamos nos registros de várias das suas atividades, indícios e provas dessa relação ativa das organizações com os agentes promotores diretos do golpe. ${ }^{10}$

Portanto, os arquivos de empresas formam um universo singular de informações sobre a sua própria história institucional, mas que também trazem elementos importantíssimos para compor o tecido das conjunturas. Ao analisar o sentido profundo do documento de Arquivo, Ana Maria Camargo faz uma síntese precisa que vale para os arquivos empresariais:

$9 \quad$ Idem, pp. 42-43.

10 Recentemente, muitas pesquisas revelam a participação ativa e passiva de muitas empresas brasileiras na promoção e manutenção do golpe militar de 1964. Sobre o tema da participação da FIESP na instauração do golpe militar e no financiamento de órgãos repressivos, consultar o capítulo "O financiamento da repressão" do relatório da Comissão da Verdade do Estado de São Paulo "Rubens Paiva". Disponivel em: http://verdadeaberta.org/relatorio/tomo-i/downloads/l Tomo Parte 1 Ofinanciamento-da-repressao.pdf (acesso em 19 jan. 2016). No Relatório da Comissão Nacional da Verdade, ver especialmente: http://cnv.memoriasreveladas.gov.br/images/pdf/relatorio/Volume\%202\%20-\%20Texto\%208.pdf 
Fica mais ou menos óbvia, a partir das ponderações feitas, a importância dos arquivos para a reconstituição das realidades do passado. E essa importância é tanto maior quanto mais amplo, profundo e duradouro é o grau de intervenção das instituições no âmbito da sociedade (como ocorre com as (âmaras municipais, as Prefeituras, os Tribunais de Justiça etc.), fazendo com que seus arquivos sejam capazes de espelhar não apenas o modo como funcionaram, mas também, por extensão, as realidades com as quais, de um modo ou de outro, se envolveram. ${ }^{11}$

Em geral, as empresas são boas produtoras de documentos de arquivo e até conseguem mantê-los razoavelmente organizados durante muito tempo, especialmente nos casos de algumas funções, como a de contabilidade e a de recursos humanos, e até relativos às funções de comando. Porém, duas grandes ordens de problemas se colocam e que tornam esses arquivos quase inacessiveis. Primeiramente, a dificuldade de preservação desses documentos no longo prazo. Em geral, empresas privadas não costumam promover gestão documental adequada, o que provoca a destruição periódica de documentos que cumpriram a função de prova para a qual foram criados (primeira idade). Assim, não há política interna que promova a avaliação documental e propicie uma "segunda idade" para tais documentos, a partir de uma avaliação arquivística. Lembrando que a manutenção da organicidade dos documentos de arquivo é crucial para a preservação da integridade da informação:

Daí a condição sui generis de que desfrutam os arquivos: o estatuto probatório de seus documentos é congênito e incide sobre as próprias atividades de que resultaram. Se o termo documento é designativo comum de todo e qualquer registro suscetivel de valor de prova, é preciso ressaltar que, nos arquivos, esse atributo não só alcança potência máxima como independe das construções discursivas que, sobretudo nos museus, a curadoria utiliza para justificar grande parcela do acervo. A manutenção da organicidade - qualidade segundo a qual os arquivos refletem a estrutura, as funções e as atividades de determinada instituiçãa, em suas relações internas e externas - é, por sua vez, requisito para que os documentos não percam a capacidade probatória que os distingue. ${ }^{12}$

A Light é um caso raro de empresa no Brasil que demonstrou senso de preservação de sua memória institucional, ainda assim, por cultura herdada de origem, segundo sugerem Vitoriano e Madio:

\begin{abstract}
A Light, por suas características de formação e de especialização na administração de empresas elétrica havia trazido para o Brasil uma cultura organizacional voltada para a formalização e regularidade dos atos e posterior registro e preservação do acervo documental produzido. Uma das características do Arquivo da Light era a "manutenção de "conjuntos documentais extremamente bem conservados (produzidos por diversos setores, de valor informativo inquestionável, embora sem valor probatório), mas dotado de uma característica fundamental: a manutenção de sua organicidade".13
\end{abstract}

São poucas as empresas no Brasil preocupadas em produzir e organizar seu arquivo histórico e quando isso ocorre, muitas vezes esses arquivos são montados para finalidades de celebração e

11 Ana Maria de Almeida Camargo. "Sobre o valor histórico dos documentos". Revista Arquivo Rio Claro, 1 (2003), pp. 11-17.

12 Ana Maria de Almeida Camargo e Silvana Goulart. Centros de memória: uma proposta de definição. Edições SESC-SP, 2015, p. 27.

13 Marcia Cristina de Carvalho Pazin Vitoriano e Telma Campanha Carvalho Madio. "Uso e funcionalidade de arquivos empresariais do setor elétrico em São Paulo: o caso Light". Labor \& Engenho v.9, n.1 (jan./mar. 2015), pp. 135-143 (aqui p. 138). 
construção de autoimagem para exploração comercial. Em sua tese, Vitoriano aprofunda algumas reflexões a esse respeito. ${ }^{14}$

Como agravante, no Brasil não há uma política voltada para o recolhimento e preservação de arquivos privados de interesse público. A Lei n 8.159 , de 08/01/1991, conhecida como "lei dos Arquivos", destina um capítulo aos arquivos privados, mas sem apontar diretrizes para políticas de recolhimento, guarda e preservação dos mesmos.

Não há uma entidade de caráter regional ou nacional capaz de, minimamente, regular sobre os arquivos privados, ficando estes à mercê de eventuais interesses e possibilidades de serem eles abrigados em arquivos públicos. As associações de classe (sindicatos, federaç̧ões e confederações) não esboçam qualquer interesse nesse sentido. ${ }^{15}$

Outro grande problema diz respeito ao hermetismo dos gestores empresariais que, em geral, negam-se a proporcionar o acesso aos arquivos de suas empresas mesmo quando estas encerram suas atividades. Não é fácil romper com a blindagem empresarial que mantém cerrada a sete chaves "segredos" patronais das mais diversas ordens.$^{16}$ Além do mais, a legislação vigente sobre acesso não abrange as instituições de direito privado, com alguma exceção, restando ao pesquisador utilizar o seu arsenal argumentativo para sensibilizar os donos de tais arquivos para Ihe permitir 0 acesso.

Desde 2011 o poder público está constrangido a promover a transparência das suas ações a partir da edição da lei $n^{\circ} 12.527$, de 18 de novembro, chamada de Lei de Acesso à Informação (LAI). Essa lei teve um impacto muito positivo em relação à transparência na administração pública, mas a sua real eficácia ainda está sendo analisada. Entretanto, certo é que os problemas para sua efetiva implementação são notórios, principalmente devido à falta de organização dos arquivos na administração pública brasileira. E, já está claro, sem arquivos organizados e disponibilizados, toda política de acesso à informação fracassa.

Esse ato normativo submete também entidades privadas, mas aquelas sem fins lucrativos:

Art. $2^{\circ}$ - Aplicam-se as disposições desta Lei, no que couber, às entidades privadas sem fins lucrativos que recebam, para realização de ações de interesse público, recursos públicos diretamente do orçamento ou mediante subvenções sociais, contrato de gestão, termo de parceria, convênios, acordo, ajustes ou outros instrumentos congêneres.

Parágrafo único. A publicidade a que estão submetidas as entidades citadas no caput refere-se à parcela dos recursos públicos recebidos e à sua destinação, sem prejuízo das prestações de contas a que estejam legalmente obrigadas.

Hoje, como ontem, permanecem as dificuldades em se localizar e ter acesso a arquivos de empresas para fins de pesquisas históricas.

14 Ver Marcia Cristina de Carvalho Pazin Vitoriano, Obrigação, controle e memória, op. cit., p. 94 et passim.

15 Sobre esse aspecto dos arquivos privados no Brasil, ver Bruna Pimentel Lopes e Georgete Medleg Rodrigues. "Os arquivos privados na legislação brasileira: do anteprojeto da lei de arquivos às regulamentações do Conarq". Revista do Arquivo, 4 (2017), disponível em: http://www.arquivoestado.sp.gov.br/revista do arquivo/04/artigo 01.php\#inicio artigo; Sônia Troitino. "De interesse público: política de aquisição de acervos como instrumento de preservação de documentos". Revista do Arquivo, 4 (2017), disponivel em: http://www.arquivoestado.sp.gov.br/revista do arquivo/04/artigo 04.php\#inicio artigo; e Marcia Cristina de Carvalho Pazin Vitoriano, "A presença de fundos privados institucionais", op. cit..

16 Sobre essa questão, há um singelo artigo da Mirta Zaida Lobato e Fernando Rocchi, que se intitula "Industria y trabajadores: el valor de los archivos como fuente documental", publicado na Revista de História Entrepasados, n 1, de 1991, da Faculdad de Filosofia y Letras de Buenos Aires. Essa publicação se encontra na biblioteca do IFCH, da Unicamp, em Campinas, São Paulo. 


\section{Tipologias documentais de arquivos de empresas}

Segundo Vitoriano, as empresas produzem documentos impelidas por três condicionantes: obrigação imposta pela legislação; controle, função relacionada ao monitoramento e fiscalização das ações, responsável pela maior parte dos documentos produzidos; e a função de memória. A autora desenvolveu quadro de classificação de funções, subfunções e atividades que são típicas de organizações privadas cuja observância auxiliará muito ao pesquisador. São elas: Constituição Jurídica, Direção institucional, Gestão das relações de trabalho, Comunicação, Gestão mercadológica e comercial, Gestão de materiais e patrimônio, Gestão financeira, Contábil-fiscal, Gestão da informação e Técnica finalística. ${ }^{17}$

0 leque de tipologias documentais produzidos cotidianamente por empresas em cada uma dessas atividades é bem vasto. É claro que há séries documentais muito ricas e com alta densidade de informações que testemunham a memória institucional e também aspectos do contexto histórico, e outras séries de rala densidade informacional. Do plano de classificação apresentado por Vitoriano, destaco três delas que considero altamente valiosas para a tessitura da história do trabalho: direção institucional, gestão das relações de trabalho e comunicação.

Os documentos que registram as funções e atividades da alta gestão das empresas são potencialmente ricos. Na pesquisa desenvolvida para o meu doutoramento me deparei com ausência quase completa de fontes primárias que me dessem acesso a informações qualificadas sobre o meu objeto de pesquisa: o Departamento Estadual do Trabalho de São Paulo (DET), órgão mediador das relações de trabalho desde 1911. Ou seja, não foi localizada a documentação administrativa desse Departamento, mas apenas um periódico publicado com certa regularidade. Restou-me a possibilidade de fontes indiretas, como documentos de outras instâncias do aparelho de Estado, de empresas, de sindicatos, associações de classe e jornais para encontrar informações sobre o DET. Fiz algumas tentativas de contato com a Federação das Indústrias do Estado de São Paulo (FIESP) para acessar arquivos, sem sucesso.

No entanto, algo inesperado aconteceu: deparei-me com uma série documental dos arquivos da FIESP em improvável local: nas estantes da biblioteca do Instituto de Filosofia e Ciências Humanas da UNICAMP (!). Refiro-me à "coleção" de circulares da FIESP, encadernada, desde 1928 até 1947. Fato inusitado, mas muito comum no Brasil. Essa riquíssima série documental de arquivo se encontrava na biblioteca da FIESP, pois fora tratada como exemplares bibliográficos devido à encadernação que lhe mantinha com lombada e "em pé", tal qual um livro. Essa biblioteca fora doada ao IFCH/Unicamp, e, assim, um arquivo de instituição privada foi parar numa biblioteca de uma universidade pública. A sorte foi minha, pois o uso das circulares da FIESP foi crucial para a minha pesquisa e está registrada na tese que se tornou livro.

Essas circulares registram comunicações das instâncias diretivas da FIESP com as empresas filiadas, com o Departamento Estadual do Trabalho, com o Ministério do Trabalho, Indústria e Comércio, com entidades de trabalhadores e com diversas instâncias do Estado paulista, inclusive com órgãos de controle, vigilância e repressão, muitas delas de caráter confidencial e sigiloso. As circulares foram fundamentais para a percepção de discursos que expressam conflitos no seio da classe dominante e seu Estado e, principalmente com as diversas frações da classe trabalhadora. ${ }^{18}$

17 Marcia Cristina de Carvalho Pazin Vitoriano. Obrigação, controle e memória, op. cit., capítulo 3.

18 Para constatar o uso intenso dessa série documental, consultar Marcelo Antonio Chaves. Trajetória do Departamento Estadual do Trabalho e a mediação das relações de trabalho (1911-1937). São Paulo: LTr, 2015, especialmente os capítulos 3 e 5. 


\section{Fichas de registros de empregados}

As fichas de trabalhadores no Brasil marcam a conflituosa política de controle social pelo Estado, em disputa com as empresas, na década de 1930. Desde janeiro de 1931, o Departamento Estadual do Trabalho se antecipou à política trabalhista federal lançando a carteira sanitária, a carteira de registro profissional e obrigando as empresas a criarem fichas de registro dos trabalhadores. 0 fichamento é um recurso administrativo que vem a atender às necessidades de controle não só pelos patrões, mas também às ações fiscalizadoras do Estado, no que diz respeito à gestão da força de trabalho pelo capital. As fichas dos operários resumem as informações que aos donos da empresa bastavam para fins gerenciais. No primeiro momento de implantação, os empresários paulistas se colocaram recalcitrantes ao controle dos trabalhadores pelo Estado, advogando que essa seria uma prerrogativa deles, empresários. ${ }^{19}$

As séries documentais dos arquivos empresariais que compõem o que Vitoriano classificou como gestão das relações de trabalho, na subfunção administração de pessoal, atividade individual do empregado são fontes primorosas que revelam aspectos da política trabalhista patronal condicionada pelo Estado e também testemunhos históricos de vestígios importantes de condições de vida de trabalhadores. Conhecidos como documentos compostos, pela sua característica de unidade documental que reúne documentos múltiplos e indissociáveis para finalidade específica, os prontuários funcionais, como são conhecidos atualmente, destacam-se por acumular e revelar aspectos da trajetória funcional dos trabalhadores nas empresas. A ficha de registro de trabalhadores deu origem ao prontuário funcional e atualmente é um dos documentos que 0 compõe. Algumas tabelas de temporalidade de documentos indicam que esse tipo documental é de guarda de longa duração por resguardarem direitos e deveres de trabalhadores e patrões, mas eliminável após cumprirem os prazos legais e precaucionais.

Quando realizei a minha pesquisa sobre a Fábrica de Cimento Perus, que resultou em dissertação de mestrado (2005), consultei alguns trabalhos acadêmicos que utilizaram fichas de trabalhadores de empresas como fontes essenciais em suas pesquisas, destacando-se: A tecelagem dos conflitos de classe na cidade das chaminés, de José Sérgio Leite Lopes ${ }^{20}$ e Negros e brancos em São Paulo (1888 - 1988), de George Reid Andrews. ${ }^{21}$

Leite Lopes utilizou pouco mais de uma centena de fichas de trabalhadores que enriqueceram a sua excepcional pesquisa de antropologia social dos operários da Companhia de Tecidos Paulista, instalada no Estado de Pernambuco.

Já o livro de Andrews é exemplar no uso dessa série documental das Companhias Jafet e São Paulo Tramway, Light na Power para fins de estudos analíticos sobre questões raciais. Andrews analisou uma amostragem representativa de 4.229 operários da Companhia Jafet e 530 da Light and Power. Esse autor realizou diversos cruzamentos dos dados preenchidos nos campos das fichas para elaborar um diagnóstico a partir de estudos de casos e formular argumentos sobre as questões que envolvem grupos de brancos e não brancos no ambiente fabril paulista.

19 Idem, capítulo 3.

20 José Sérgio Leite Lopes. A tecelagem dos conflitos de classe na cidade das chaminés. São Paulo/ Brasília: Marco Zero/ UnB/ CNPq, 1988.

21 George Reid Andrews. Negros e brancos em São Paulo (1888 - 1988). Bauru: EDUSC, 1991. Na dissertação de Paulo Fontes, datada de 1996, defendida na UNICAMP, Trabalhadores da Nitro Química: a fábrica e as lutas operárias nos anos 50, página 21, o autor afirma ter utilizado como fontes de pesquisa "Documentos internos, fichas de trabalhadores, fotografias e principalmente a coleção completa do informativo interno da companhia nos anos cinquenta, o Nitro Jornal". Entretanto, essas fontes aparecem apenas marginalmente e de forma difusa. 


\section{$5 \mathrm{~A}$ primeira fábrica de cimento vista pelas fichas de trabalhadores}

A minha dissertação de mestrado, defendida na UNICAMP em 2005, versou sobre a primeira fábrica de cimento instalada no Brasil em 1925, tendo como foco central uma descrição analítica das primeiras gerações de trabalhadores da fábrica, baseada na dissecação e cruzamento de dados de 1.500 fichas de trabalhadores.

As fichas da Fábrica de Cimento Perus continham dados de registros funcionais mais ou menos padronizados: fotografia de rosto, nome, filiação, endereço, local de trabalho (no caso de mais de uma unidade produtiva da empresa), data de nascimento, idade, país de origem, local de nascimento, sexo, grau de instrução, datas de admissão e de demissão, salário, cor, função/cargo, nome de dependentes, assinatura e alguns campos abertos para observações e até registro de acidentes de trabalho.

Utilizei os dados fornecidos pelas fichas procurando algumas caracterizações gerais que informassem os perfis dos trabalhadores da fábrica de cimento e, a partir de cruzamento entre os dados e com outras fontes de pesquisa realizei comparações a fim de inferir características representativas de parte do universo contraditório da classe trabalhadora brasileira no período.

Com isso consegui construir um arquétipo de informações que serviram e servirão para subsidiar temas candentes da sociedade: aspectos sobre questão de gênero nas fábricas; cor, idade e nacionalidade relacionados com estabilidade na empresa, qualificação, ascensão funcional, benefícios trabalhistas, instrução, salários e jornada de trabalho. 0 altíssimo número de acidentes de trabalho também foi cruzado com esses dados além de identificar as regiões do corpo atingidas.

Ou seja, com um simples fragmento do universo documental de uma empresa, consegui produzir "matérias-primas" semielaboradas para fundamentar larga abrangência temática que extrapola em muito as fronteiras da planta empresarial.

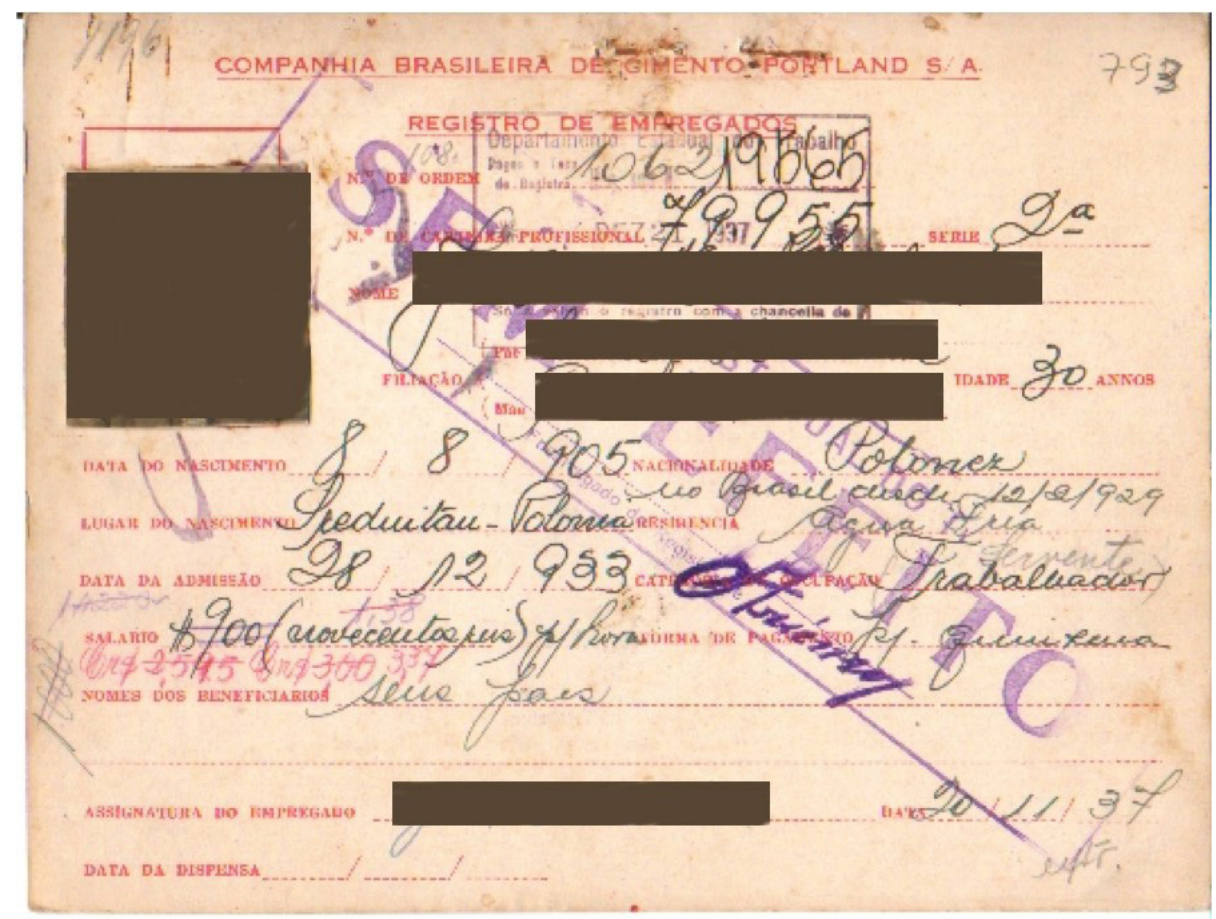




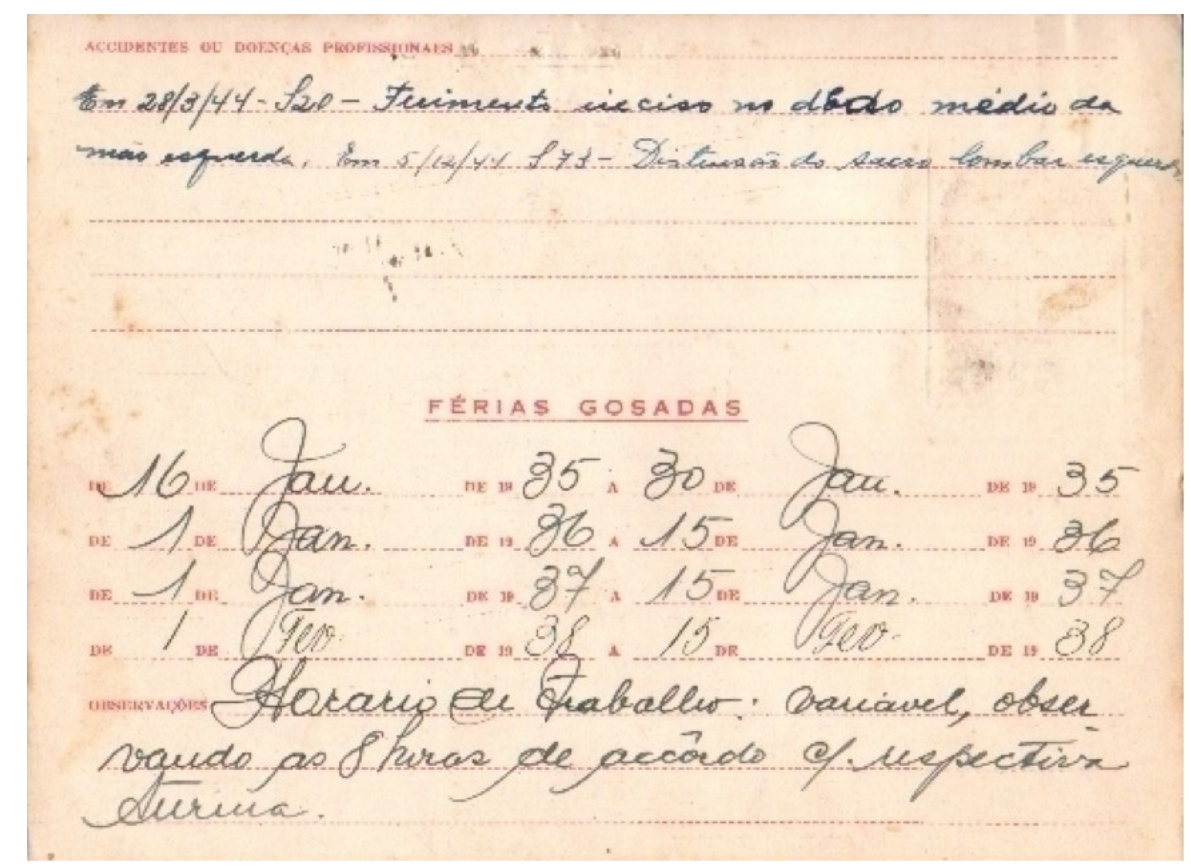

Figuras 1 e 2: Frente e verso de ficha de trabalhador da Fábrica de Cimento Perus da década de 1930. Os originais dessas fichas, à época da pesquisa, encontravam-se em um dos depósitos então existentes ainda pertencentes ao antigo proprietário da fábrica. (N.E.: A identidade do trabalhador foi resguardada).

\section{Conclusão}

Os arquivos de empresas, no seu sentido mais pleno, formam um manancial de informações que precisam ser preservados para oferecerem um leque maior e mais diversificado para as pesquisas científicas. As próprias plantas e seu entorno são objetos fascinantes de pesquisas arqueológicas a revelarem costumes e padrões técnicos de uma época.

Informações de arquivos de empresas podem ser encontradas nas unidades ativas, em organizações desativadas que ainda guardam parte dos seus acervos por obrigações legais e também por razões casuais; em associações patronais; nas juntas comerciais; em órgãos de controle do Estado (instâncias correcionais e de justiça); organismos estatais da administração direta (departamentos, ministérios e secretarias) e indireta (órgãos de pesquisa e informações), em especial órgãos estatais voltados para a função de relações de trabalho, saúde e fazendária; em arquivos de câmaras legislativas, em bibliotecas e museus da cidade; em centros de memória, principalmente em bairros de localização das sedes das empresas e em documentação policial. Esses são alguns caminhos possíveis onde se pode encontrar vestígios de documentos de empresas. 